\title{
Estimation of prostate size by trans-rectal ultrasound and its correlation with DRE and endoscopic grading
}

\author{
Gupta S. ${ }^{1}$, Saraf S. ${ }^{2}$, Kumar Pal D. ${ }^{3 *}$ \\ DOI: https://doi.org/10.17511/ijmrr.2020.i01.10 \\ 1 Sandeep Gupta, Associate Professor, Department of Urology, Institute of Post Graduate Medical Education \& Research, Kolkata, West \\ Bengal, India. \\ 2 Siddharth Saraf, Post-Doctoral Trainee, Department of Urology, Institute of Post Graduate Medical Education \& Research, Kolkata, West \\ Bengal, India. \\ 3* Dilip Kumar Pal, Professor \& Head, Department of Urology, Institute of Post Graduate Medical Education \& Research, Kolkata, West \\ Bengal, India.
}

Aim: Digital rectal examination (DRE) grading and the grade of prostatomegaly on cystoscopy are routinely used in clinical practice, but its correlation to prostate volume is understudied. This study was done to assess the correlation of DRE and endoscopic grading with the prostate volume on trans-rectal ultrasound (TRUS). Materials and Methods: This study was carried out in 101 eligible patients with prostatomegaly. Each patient was evaluated for three parameters, prostate volume by TRUS examination, DRE and endoscopic grading on cystoscopy. Pearson correlation coefficient was calculated to find the correlation between variables, $\mathrm{p}<0.05$ was taken to be statistically significant. Data were analyzed using the Epi Info (TM) 7.2.2.2. Results: Significant positive correlation $(p<0.001)$ was found between TRUS Volume and DRE grading (Pearson Correlation=0.945) and TRUS volume and Endoscopic grading (Pearson Correlation=0.949). Both the grading were also significantly positively correlated (Pearson Correlation=0.989, p<0.001). Conclusion: Our attempt for correlating the digital rectal grading and endoscopic grading with prostate volume is satisfactorily validated in the clinical setting. These grades are sufficient to provide a rough estimation of the prostate volume and to classify patients with prostatomegaly.

Keywords: DRE, TRUS, Endoscopic grading, Prostate size

Corresponding Author

Dilip Kumar Pal, Professor \& Head, Department of Urology, Institute of Post Graduate Medical Education \& Research, Kolkata, West Bengal, India.

Email: urologyipgmer@gmail.com

\section{How to Cite this Article}

Gupta S, Saraf S, Pal DK. Estimation of prostate size by trans-rectal ultrasound and its correlation with DRE and endoscopic grading. Int J Med Res Rev. 2020;8(1):63-68.

Available From

https://ijmrr.medresearch.in/index.php/ijmrr/article/ view/1140
To Browse

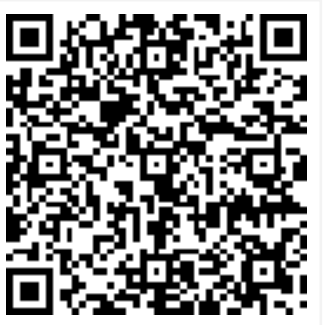

Manuscript Received 2019-12-10

Conflict of Interest No (C) 2020 by Sandeep Gupta, Siddharth Saraf, Dilip Kumar Pal and Published by Siddharth Health Research and Social Welfare
Society. This is an Open Access article licensed under a Creative Commons Attribution 4.0 International License https://creativecommons.org/licenses/by/4.0/ unported [CC BY 4.0].

\author{
Review Round 2 \\ 2019-12-27

\section{Review Round 3 $8 \%$} \\ Plagiarism X-checker
}

Riew Round 1 2019-12-20
Accepted 2020-01-03

Note 


\section{Introduction}

Benign prostatic hyperplasia (BPH) is rare in men younger than 40 years, but it is found in over half of 60-year-old men and is found in almost all 80-yearold men [1]. With the increase in life expectancy, the incidence of BPH is also on the rise. Trans-rectal ultrasonography (TRUS) is routinely used by radiologists and urologists to diagnose $\mathrm{BPH}$. TRUS evaluates the size, shape, presence of adenoma, and anatomy of the prostate relatively accurately and noninvasively. TRUS is also used for taking guided tru-cut biopsies in cases suspicious of carcinoma of the prostate.

Digital Rectal Examination (DRE) is the most ancient method of prostate examination. It is indicated in all the men presenting with urinary tract symptoms. An effective DRE requires a meticulous, thorough, and skilful examination technique that is usually acquired only after a fairly long learning curve. There have been various attempts to standardize the DRE grading in the past of which the work of Romero et al and recently Lodh et al has been most widely accepted $[2,3]$. Estimation of prostate size is important to guide the most appropriate pharmacological or surgical approach. However, symptom severity, degree of urodynamic obstruction, or treatment outcomes does not precisely correlate with prostate size [4]. DRE provides sufficiently accurate measurement in most patients, but the correlation of DRE grades of the prostate with prostate volume remains understudied.

Cystourethroscopic examination of the bladder and urethra remains the gold standard for the diagnosis of lower urinary tract disorders. A prior cystoscopic assessment is generally not necessary for surgical management of the prostate and it can be done at the time of the procedure. Cystoscopy is indicated for haematuria and to exclude urethral stricture, bladder stones, bladder diverticula or bladder cancer in patients with benign prostatic hyperplasia. Endoscopic grading for prostate is being widely used in clinical practice but its correlation to actual prostate volume and DRE findings has not been studied in the past [5]. In our best knowledge, there hasn't been any study regarding the endoscopic grading or its comparison to prostate volume in the past.

The study is designed to assess the prostate volume in patients with prostatomegaly by TRUS and its correlation with subsequent endoscopic grading
And DRE grading. This study also aims to validate these grades in a clinical setting.

\section{Materials and Methods}

Study Setting and Design: This was a prospective study conducted in the Department of Urology, Institute of Post Graduate Medical Education \& Research (IPGME\&R), Kolkata from October 2017 to June 2018.

Inclusion criteria: A total of 101 patients with prostatomegaly planned for endoscopic surgical intervention were included in the study.

Exclusion criteria: Patients with suspicion of carcinoma of the prostate, anal fissures, urethral strictures, patients with bony abnormality restricting positioning were excluded from the study.

Data collection: The parameters studied were prostate volume estimation by TRUS, the grade of the prostate on DRE and grade of the prostate on endoscopy. This study was done in a blinded fashion. A single trained urologist performed the TRUS with a $7.5 \mathrm{MHz}$ endo-cavitary probe after adequate bowel preparation in the left lateral decubitus position with 90 degrees flexion at hips and knees. The volume estimation was done by using ellipsoid formula i.e. volume $(\mathrm{ml})=0.523 \mathrm{x}$ width $(\mathrm{cm}) \times$ height $(\mathrm{cm}) \times$ length $(\mathrm{cm})[6]$.

DRE was performed by another trained urologist after the patient had voided. DRE was performed in a modified lithotomy position in which a patient rests on his back with hips and knees flexed and abducted. The current study used the DRE grading described by Lodh et al (Table 1) involving comment on the accessibility of upper limit, depth of lateral sulcus and condition of the median sulcus or posterior surface [2].

The endoscopic grade of the prostate was noted by a senior urologist during the intervention. The current study used the endoscopic grading mentioned by Barnes et al involving the comment on intra-urethral lateral lobes of the prostate (Table 2) [5].

Data analysis: Statistical Analysis was performed with the help of Epi Info (TM) 7.2.2.2. Descriptive statistical analysis was performed to calculate the means with corresponding standard deviations (SD). The test of proportion was used to find the Standard Normal Deviate $(Z)$ to compare the different proportions. Pearson correlation coefficient was calculated to find the correlation between variables. 
One way analysis of variance (ANOVA) followed by Tukey's test was used to compare more than one meaning at a time.p $<0.05$ was taken to be statistically significant.

Ethical consideration and permission: Ethical approval was acquired from the institutional ethics committee. Informed risk consent was acquired from all the patients.

Table-1: DRE grading [2].

\begin{tabular}{|l|l|l|l|}
\hline \multicolumn{5}{|c|}{ DRE GRADING } \\
\hline $\begin{array}{l}\text { Grade of } \\
\text { prostatomegaly }\end{array}$ & $\begin{array}{l}\text { limit of prostate } \\
\text { limility of upper }\end{array}$ & $\begin{array}{l}\text { Depth of } \\
\text { lateral sulcus }\end{array}$ & $\begin{array}{l}\text { Condition of the } \\
\text { median sulcus }\end{array}$ \\
\hline I & Easy & 1 finger width & Unnoticed/ shallow \\
\hline II & With little effort & $>1$ but $<2$ & Prominent median \\
finger width & sulcus \\
\hline III & With marked difficulty & 2 finger width & Obliterated \\
\hline
\end{tabular}

Table-2: Endoscopic grading [5].

\begin{tabular}{|l|l|}
\hline \multicolumn{2}{|c|}{ Endoscopic grading } \\
prostatomegaly & Intraurethral Lateral Lobes \\
\hline I & $\begin{array}{l}\text { Lateral lobes bulge inward but do not touch in the } \\
\text { midline }\end{array}$ \\
\hline II & Lateral lobes just touch in the midline \\
\hline III & Lateral lobes touch in the midline for 2 to $3 \mathrm{~cm}$ \\
\hline IV & Lateral lobes touch in the midline for more than 3 \\
\hline
\end{tabular}

\section{Results}

The mean age (mean \pm s.d.) of the patients was $60.18 \pm 10.84$ years with range $40-80$ years. Most of the patients $(51.4 \%)$ were age $\geq 60$ years which was significantly higher than another age group $(Z=2.97 ; p<0.001)$.

The mean TRUS Volume (mean \pm s.d.) of the patients was $60.14 \pm 21.80 \mathrm{gm}$ with range $25-122$ gm. Most of the patients $(60.4 \%)$ were with TRUS Volume $\geq 50 \mathrm{gm}$. Only $5.9 \%$ were with TRUS Volume $\geq 100 \mathrm{gm}$.

The mean DRE grading(mean \pm s.d.) of the patients was $2.51 \pm 0.93$ with range 1 - 4 . Most of the patients (37.6\%) were with DRE Grading as III but it was not significantly higher $(Z=0.87 ; p>0.05)$. The mean Endoscopic grading(mean \pm s.d.) of the patients was $2.50 \pm 0.93$ with range $1-4$. Most of the patients (35.6\%) were with Endoscopic Grading as III but it was not significantly higher $(Z=0.28 ; p>0.05)$.
The digital rectal Grades I-IV corresponded roughly to the TRUS volume of $30.50 \pm 2.85 \mathrm{ml}, 47.91 \pm 5.43$ $\mathrm{ml}$, 67.53 $\pm 6.07 \mathrm{ml}$, and $99.13 \pm 9.97 \mathrm{ml}$, respectively. The endoscopic Grades I-IV corresponded roughly to the TRUS volume of $30.50 \pm 2.85 \mathrm{ml}, 48.41 \pm 5.69 \mathrm{ml}, 68.14 \pm 5.59 \mathrm{ml}$, and $99.13 \pm 9.97 \mathrm{ml}$, respectively (Table 3,4). Significant positive correlation $(p<0.001)$ was found between TRUS Volume and DRE grading (Pearson Correlation=0.945) and Endoscopic grading (Pearson Correlation=0.949) [Figure 1,2]. Both the grading was also significantly positively correlated (Pearson Correlation $=0.989, \mathrm{p}<0.001$ ) [Figure 3].

Table-3: Comparison of TRUS volume according to the DRE grading of the patients

\begin{tabular}{|l|l|l|l|}
\hline \multicolumn{1}{|c|}{$\begin{array}{c}\text { DRE } \\
\text { Grading }\end{array}$} & Number & \multicolumn{1}{|c|}{ TRUS volume (in gm) Mean \pm} & \multicolumn{1}{c|}{$\begin{array}{c}\text { Range } \\
\text { s.d. }\end{array}$} \\
\hline I & 16 & $30.50 \pm 2.85$ & $25-35$ \\
\hline II & 32 & $47.91 \pm 5.43$ & $35-57$ \\
\hline III & 38 & $67.53 \pm 6.07$ & $54-79$ \\
\hline IV & 15 & $99.13 \pm 9.97$ & $85-122$ \\
\hline
\end{tabular}

Table-4: Comparison of TRUS volume according to the endoscopic grading of the patients

\begin{tabular}{|l|l|l|l|}
\hline \multicolumn{1}{|c|}{$\begin{array}{c}\text { Endoscopic } \\
\text { Grading }\end{array}$} & Number & $\begin{array}{c}\text { TRUS volume (in gm), } \\
\text { Mean } \pm \text { SD }\end{array}$ & \multicolumn{1}{|c|}{$\begin{array}{c}\text { Range } \\
\text { (gms) }\end{array}$} \\
\hline I & 16 & $30.50 \pm 2.85$ & $25-35$ \\
\hline II & 32 & $48.41 \pm 5.69$ & $35-59$ \\
\hline III & 38 & $68.14 \pm 5.59$ & $56-79$ \\
\hline IV & 15 & $99.13 \pm 9.97$ & $85-122$ \\
\hline
\end{tabular}

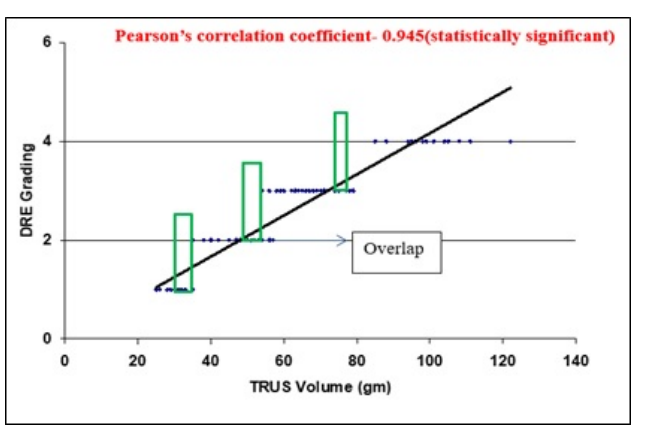

Fig-1: Correlation between DRE grading and TRUS volume.

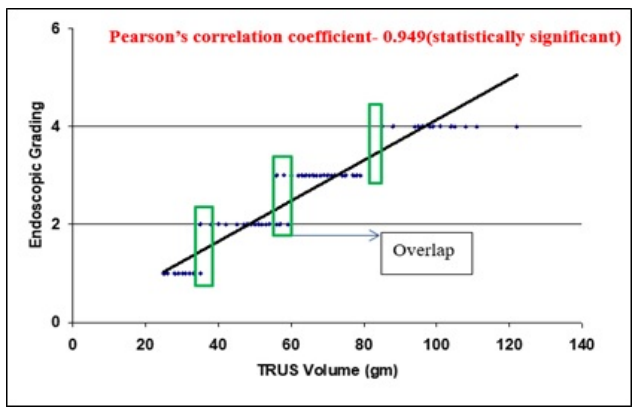


Fig-2: Correlation between endoscopic grading and TRUS volume.

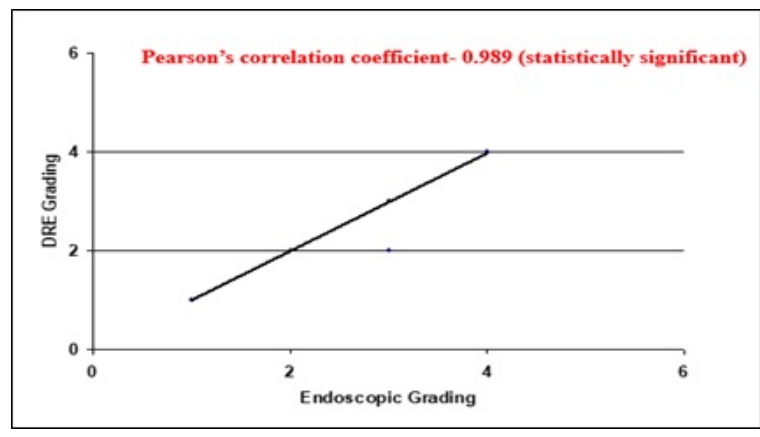

\section{Fig-3: Correlation between DRE grading and TRUS grading.}

\section{Discussion}

Estimation of the prostate volume is an important aspect of preoperative workup in patients of prostatomegaly. It aids in choosing whether the patient needs medical or surgical treatment [7]. It also helps in the prediction of the duration of surgery and blood loss in surgeons with little experience [8].

However, prostate size does not correlate well with the symptoms, as patients with large prostates can have mild symptoms while those with smaller ones might present with bothersome symptoms. Estimation of prostate size does help in deciding the use of combination pharmacotherapy [9].

Prostate size estimation can be done radiologically or it can be done clinically by DRE or endoscopy. Transabdominal ultrasound, TRUS, threedimensional ultrasound all come in the armamentarium for prostate volume estimation. However, TRUS has been most widely used due to the easy availability and reasonable accuracy.TRUS has also been observed to have inter-observer variability [10].

Kim et al., in a Korean study showed maximum accuracy and minimum inter-observer variability with three-dimensional ultrasound while admitting the increased cost and additional duration of procedure as compared to TRUS and transabdominal ultrasound [11]. The current study used TRUS in the present study for prostate volume estimation due to its availability at our institute and accuracy.

DRE is a very important clinical tool for patients with prostatomegaly. It has been shown to be a poor
Predictor of prostate volume as compared to TRUS [12]. A study showed that DRE despite the high diagnostic value, is subjective and needs to be objectified by means of ultrasound examination [13]. Also one study showed that estimation of prostate volume by DRE appears bigger than evaluated by TRUS [14].

In a study, Cheng et al have shown that there is a statistically significant discrepancy in estimated prostate volume when done by a junior trainee compared to a trained urologist [15]. Grading for DRE is also far from simplicity.

Here the current study used DRE grading mentioned by Lodh et al which is a modification of DRE grading described by Romero et al due to its simplistic nature $[2,3]$. The size of prostate lobes on DRE is not a criterion as to the size of their protrusion into the bladder.

When only the median lobe is enlarged, prostate assessment through DRE may be normal [16]. There have been several attempts to standardize DRE grading in the past. Barnes et al in 1959 used encroachment of prostate into the rectal lumen with the encroachment of $1-2 \mathrm{~cm}, 2-3 \mathrm{~cm}, 3-4 \mathrm{~cm}$ and more than $4 \mathrm{~cm}$ corresponding to grades I, II, III and IV respectively [5].

Recently, a study used the DRE procedure based on the width of the posterior surface area using a three-setting scale, where scale 0 is < two widths of the finger, 1 is $\geq$ two but $<$ three widths of the finger, and 2 are $\geq$ three widths of the finger [17].

Fingertip assessment was used by Reis et al., considering the area of prostate covered by one fingertip as 10 cubic meters. Thus for 4 fingertip impressions on the posterior surface of the prostate was inferred as $40 \mathrm{cc}$ volume [18].

Romero et al.,[3] documented a volume of $20 \mathrm{~g}$ for Grade I, $30 \mathrm{~g}$ for Grade I/II, $40 \mathrm{~g}$ for Grade II, $50 \mathrm{~g}$ for Grade II/III, $60 \mathrm{~g}$ for Grade III and $80 \mathrm{~g}$ or greater for Grade IV in their study.

In their study Lodh, et al concluded that estimation of prostate size may be overestimated or underestimated by DRE but it gives a rough idea of prostate volume estimation [2].

Cystourethrosopic examination of the prostate is not a necessity but is indicated in cases of haematuria, mild prostatomegaly with bothersome lower urinary tract symptoms, bladder stones, etc. An endoscopic grading is widely used in clinical practice and is an 
Important part of operative findings. The research team did extensive web research but could not find any standardized grading for prostate on endoscopy.

For this study, the team used the endoscopic grading described by Barnes in 1959, based on the length of intra-urethral lateral lobes of the prostate [5]. Grade I being lateral lobes bulge inward but do not touch in the midline, grade II with lateral lobes just touch in the midline, grade III with lateral lobes touching in the midline for $2-3 \mathrm{~cm}$ and grade IV with lateral lobes touching in the midline for more than 3 $\mathrm{cm}$.

The current study did this study to look for the correlation between the DRE grading and endoscopic grading with the prostate size on TRUS. The digital rectal Grades I-IV corresponded roughly to the TRUS volume of $30.50 \pm 2.85 \mathrm{ml}, 47.91 \pm 5.43$ $\mathrm{ml} 67.53 \pm 6.07 \mathrm{ml}$, and $99.13 \pm 9.97 \mathrm{ml}$, respectively. The endoscopic Grades I-IV corresponded roughly to the TRUS volume of $30.50 \pm 2.85 \mathrm{ml}, 48.41 \pm 5.69 \mathrm{ml}, 68.14 \pm 5.59 \mathrm{ml}$, and $99.13 \pm 9.97 \mathrm{ml}$, respectively.

The current study also looked for whether DRE grades correlated well to endoscopic grades. In the present study, it was found that for both DRE and Endoscopic grades there was overlap between Grade I and II in TRUS volumes between 35-40gms. Likewise, there was overlap between Grade II and III with TRUS volumes of 54-59gms.

The current study did not find any overlap between grades III and IV. A small sample size in grade IV can be a reasonable explanation for that. In four of our patients, the endoscopic grading overestimated the DRE grade however in three of them it was underestimated.

However, a single-center study, small sample size, lack of standardized endoscopic grading were our noteworthy limitations.

\section{Conclusion}

Despite their inaccuracies, the digital rectal examination grading and endoscopic grading continue to be widely used in clinical practice. As prostate volume estimation is an important aspect of preoperative workup and the availability of TRUS is of the question at peripheral centers, these gradings can be useful alternatives for urologists in the management of prostatomegaly.

\section{What does the study add to the existing knowledge}

The current study validates their use for a rough estimation of prostate volume. However larger studies are required in the future to consolidate

Their credibility.

\section{Author's contributions}

\author{
Dr. Sandeep Gupta: DRE and TRUS analysis \\ Dr. Siddharth Saraf: DRE and TRUS analysis \\ Dr. Dilip Kumar Pal: Manuscript preparation
}

\section{Reference}

01. Chaple CR, MacDiarmid SA. Voiding difficulty, In- Chaple C, MacDiarmid S, eds, Urodynamics. Made easy, 2 ed, Vol 1, Chapt 4, London- WB Saunders, Harcourt Publishers Limited. 2000, pp- 75-76.

[Crossref]

02. Lodh B, Sinam RS, Singh KA. Digital rectal grading of benign prostatic hyperplasia- Where does it stand today?. J Mahatma Gandhi Inst Med Sci. 2016;21(2)40-45.

doi: [Article] [Crossref]

03. Romero F, Romero A, Filho T, Kulysz D, Oliveira F, Filho R. The prostate exam. Health Edu J. 2011;71(2)239-250. doi: [Article] [Crossref]

04. Roehrborn C, Chinn H, Fulgham P, Simpkins $K$, Peters $P$. The Role of Transabdominal Ultrasound in the Prostatic Hypertrophy. J Urol. 1986;135(6)1190-1193. doi: [Article] [Crossref]

05. Barnes RW, Bergman RT, Hadley HL. Indications for endoscopic surgery, In- Endoscopy. Encyclopedia Urol, Springer, Berlin, Heidelberg. 1959 vol 6.

[Crossref]

06. Terris MK, Stamey TA. Determination of prostate volume bytransrectal ultrasound. J Urol. $1991 ; 145$ (5)985-987. doi: [Article] [Crossref]

07. Madersbacher S, Marberger M. Is transurethral resection of theprostate still justified?. BJU Int. $1999 ; 83(3) 227-237$.

doi: [Article] [Crossref] 
08. Aus G, Bergdahl S, Hugosson J, Norlén L. Volume determinationsof the whole prostate and of adenomas by transrectal ultrasoundin patients with clinically benign prostatic hyperplasia- correlationof resected weight, blood loss and duration of operation. $\mathrm{Br} \mathrm{J}$ Urol. $1994 ; 73(6) 659-663$.

doi: [Article] [Crossref]

09. Boyle P, Gould AL, Roehrborn CG. Prostate volume predicts outcome of treatment of benign prostatic hyperplasia with finasteridemeta-analysis of randomized clinical trials. Urol. $1996 ; 48(3) 398-405$.

doi: [Article] [Crossref]

10. Bates TS, Reynard JM, Peters TJ, Gingell JC. Determination ofprostatic volume with transrectal ultrasound- A study of intraobserverand interobserver variation. J Urol. 1996;155(4)1299-1300.

doi: [Article] [Crossref]

11. Kim S, Kim S. Correlations between the Various Methods of Estimating Prostate VolumeTransabdominal, Transrectal, and ThreeDimensional US. Korean J Radiol. 2008;9(2)134-139.

doi: [Article] [Crossref]

12. Roehrborn C, Girman C, Rhodes T, Hanson K, Collins G, Sech $S$ et al. Correlation between prostate size estimated by digital rectal examination and measured by transrectal ultrasound. Urol. 1997;49(4)548-557.

[Article] [Crossref]
13. Streich $U$, Rockstroh $H$, Anger $G$, Weck $B$, Millner $R$. Objective determination of prostate size with ultrasound. Z Urol Nephrol. $1980 ; 73(8) 577-581$.

[Crossref]

14. Smith $\mathrm{HJ}$, Haveland $H$. Pre-operative and post-operativevolumetry of the prostate by transabdominal ultrasonography. $\mathrm{Br} \mathrm{J}$ Urol. 1982;54(5)531-535. doi: [Article] [Crossref]

15. Cheng WC, Ng FC, Chan KC, Cheung YH, Chan $W L$, Wong SW. Interobserver variation of prostatic volume estimation with digital rectal examination by urological staffs with different experiences. Int Braz J Urol. $2004 ; 30(6) 466-471$. doi: [Article] [Crossref]

16. Lane TJ. A note on rectal examination of the adenomatous prostate. Ir J Med Sci. $1940 ; 15 ; 322-326$.

[Crossref]

17. Tsui KH, Liu CY, Lui JM, Lee ST, Tan RP, Chang PL. Direct observation of procedural skills to improve validity of students' measurement of prostate volume in predicting treatment outcomes. Urol Sci. 2013;24(3)84-88.

doi: [Article] [Crossref]

18. Reis LO, Simão AF, Baracat J, Denardi F, Gugliotta A. Digital rectal examination standardization for inexperienced handsTeaching medical students. Adv Urol. $2013 ; 797096$. doi: [Article] [Crossref] 